\title{
Viabilidade de Microcápsulas com Lactobacillus acidophilus Durante Estocagem em Diferentes Temperaturas
}

Greice Carine Raddatz (I), Mariana de Araújo Etchepare (I), Gabriela Poletto (I), Maria Fernanda da Silveira Cáceres de Menezes (I), Juliano Smanioto Barin (I), Carlos Pasqualin Cavalheiro (I), Augusto Tasch Holkem (I), Thaiane Marques da Silva (I), Caroline Posser Simeoni (I), Cristiano Ragagnin de Menezes (I)

(I) UFSM - Universidade Federal de Santa Maria (Santa Maria-Avenida Roraima)

\section{Resumo}

Microencapsulação é o processo de empacotamento de materiais em cápsulas extremamente pequenas e vem sendo cada vez mais utilizado para aumentar a resistência de microrganismos probióticos contra condições adversas. O objetivo deste trabalho foi avaliar a viabilidade de microcápsulas com Lactobacillus acidophilus durante estocagem em temperatura de congelamento e de refrigeração. A produção das microcápsulas foi realizada através da técnica de extrusão/aspersão. Foram preparadas duas soluções distintas, a primeira solução contendo $1 \%$ de alginato de sódio (ALG) e outra contendo $1 \%$ de alginato de sódio $+1 \%$ de Hi-maize (prebiótico) que recebeu tratamento com quitosana (AHQ). O probiótico utilizado foi o Lactobacillus acidophilus. As microcápsulas foram armazenadas úmidas e estocadas em temperatura de $-18^{\circ} \mathrm{C}$ e $7^{\circ} \mathrm{C}$. Visando determinar o tempo de viabilidade das micropartículas, a enumeração de células viáveis foi realizada a cada 15 dias, num período de 135 dias de estocagem. Na temperatura de congelamento observou-se que as microcápsulas revestidas somente com alginato de sódio (ALG) perderam sua viabilidade aproximadamente em 60 dias. No entanto, o tratamento AHQ no final de 135 dias de estocagem foi o único que

\footnotetext{
Referência:

Greice Carine Raddatz, Mariana de Araújo Etchepare, Gabriela Poletto, Maria Fernanda da Silveira Cáceres de Menezes, Juliano Smanioto Barin, Carlos Pasqualin Cavalheiro, Augusto Tasch Holkem, Thaiane Marques da Silva, Caroline Posser Simeoni, Cristiano Ragagnin de Meneze. Viabilidade de Microcápsulas com Lactobacillus Acidophilus Durante Estocagem em Diferentes Temperaturas. In: Anais do 12 Congresso Latinoamericano de Microbiologia e Higiene de Alimentos - MICROAL 2014 [= Blucher Food Science Proceedings, num.1, vol.1]. São Paulo: Editora Blucher, 2014. 
manteve estabilidade acima dos valores recomendados para a vida de prateleira de um produto probiótico ( $\mathrm{p}<0,05)$, mostrando assim que a adição de prebiótico e quitosana conferiu maior proteção aos microrganismos até os 135 dias. Já na temperatura de $7^{\circ} \mathrm{C}$, observa-se que no dia 15 , houve uma redução significativa $(3,08 \log )$ nas microcápsulas de alginato de sódio (ALG). Essa redução apresentou menor valor (1,63log) no tratamento com adição de hi-maize e quitosana (AHQ). A partir do dia 75, o tratamento ALG já havia perdido sua estabilidade com contagens de $5,89 \pm 0,05 \log \mathrm{UFC} / \mathrm{ml}$. O tratamento AHQ, apresentou viabilidade até o dia 105 de armazenamento.Pode-se observar que a temperatura de congelamento apresentou melhores resultados de viabilidade e que a adição do prebiótico e da quitosana, melhorou significativamente a sobrevivência dos microrganismos independente da temperatura analisada.

Palavras-Chave: estocagem, Lactobacillus acidophilus , microencapsulação, prebiótico, quitosana

Agência de Fomento: 